\title{
ANALYSIS OF ROBOTIC CAR WITH GRIPPER CONTROLLED BY GESTURE
}

\author{
Mohit Agarwal $^{1}$, Mukesh Chheta ${ }^{2}$, Aliraza Hasan ${ }^{3}$, Sambridhi Priya ${ }^{4}$ \\ ${ }^{1,2,3,4}$ Student, Department of Electronics \& Telecom, B.V.M. Engineering, College, Anand, Gujarat, India
}

\begin{abstract}
In today's world there are many tasks in various fields which consist of manufacturing, transportation, assistance, etc. which requires humans to work, sometimes it comes to their limitation in many of the task/fields due to their disabilities or because of lack of availability of human labor. Tosubstitute them, robots were introduced which does many of the tasks for the human as per the function given. Robots make the abilities of the human to extend to a new era. Advanced, high-performance robots are used today in automobile manufacturing and aircraft assembly, and electronics firms use robotic devices together with other computerized instruments to sort or test finished products. Due to the demand of intelligent systems in every field of technology, automated systems are preferred much for the betterment of the society. The main objective here is the analysis on the robot, which is able to rover around the world and also can be able to pick up the object using the gripper attached to it. The movement of palm of a person gives motion to the bot either to rover orpick up some object around its region. The robot design can be used in varied applications in biomedical-for surgery from a distance, it will also be helpful in defense- where actual precision is needed to their movement(for instance to diffuse the bomb), it can also be useful to a disabled person-the movement of his legs can control the robot with most precision matching to the human performance. The robot can be modified to make the use in industries to control the hand precised knob where the person physically is restricted to enter and requires precision of the human hand, this robot can be useful to control such switches from the gesture of hand inside the cabin.
\end{abstract}

Keywords: Robotic Car, Gesture of Hand, Robots

\section{INTRODUCTION}

In this era of robotics the world needs to be more advance and to fulfill this, robots should understand the human in every aspect. Here the interface is gesture through which the car is being controlled over RF module. The assigned gesture movement to make the robot locomotive and grab motion,the gesture of the human is recognized using MPU-
6050 module which is an accelerometer/gyroscope and detects the gesture of human as its position varies with hand movement which is analog signal and then it is converted to a 4 bit digital pulse using a microcontroller ARDUINO UNO. The flow diagram for the project is as shown in fig1

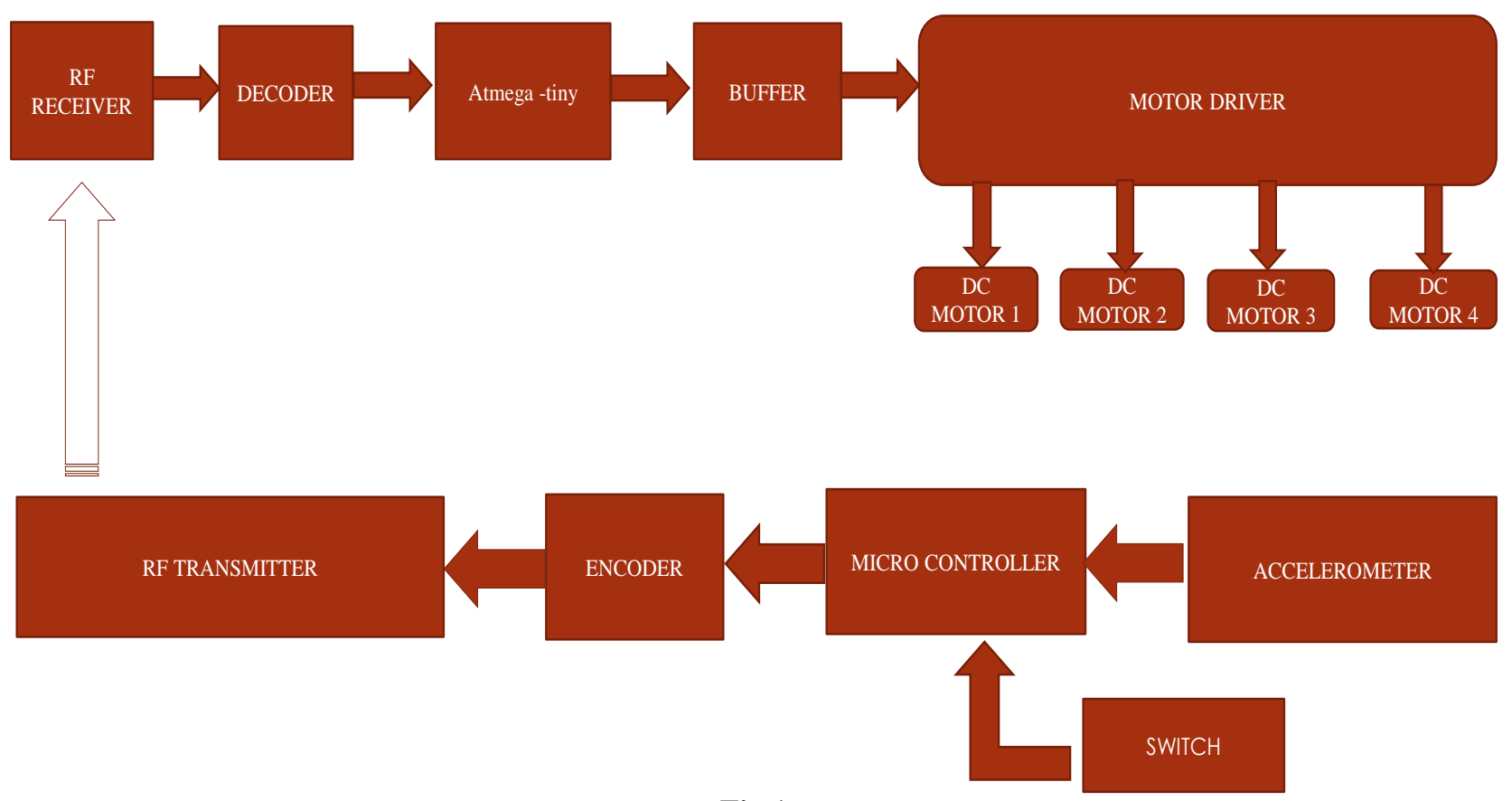

Fig 1 
The overall prototype can be divided into two part:

(i) Transmitter section and

(ii) Receiver section.

\section{BLOCK DIAGRAM OF TRANSMITTER}

It is a part of the project that makes the interface of hand gesture and switch with digital world and transmits to the robocar. The section is divided in three parts:

(i) Transducer

(ii) Converter

(iii) Transmitter

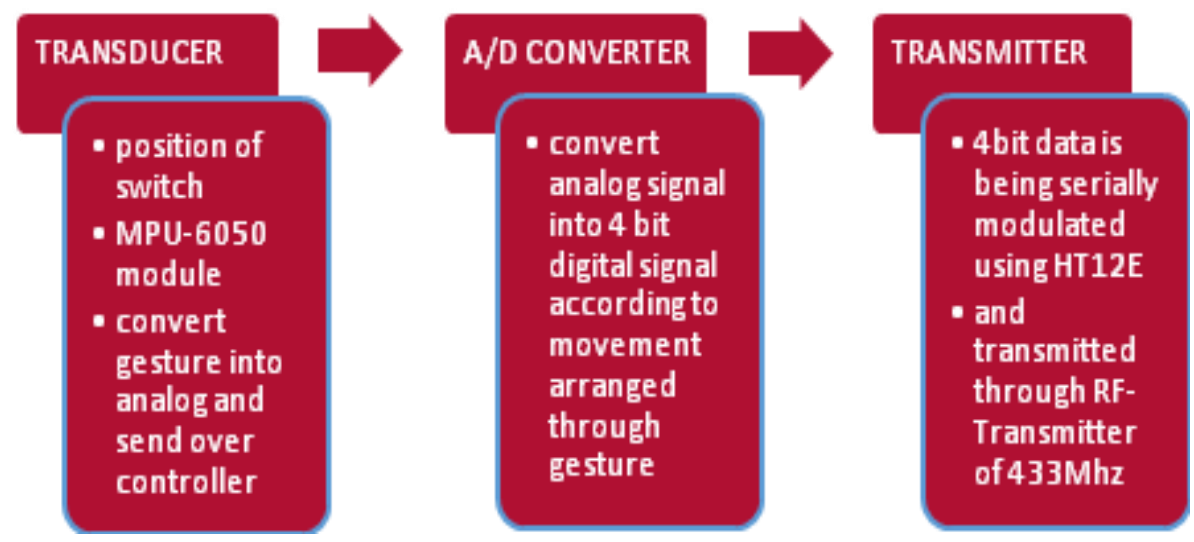

Fig 2

\subsection{Transmitter: MPU-6050 Module}

We interface or control the machine with our hand movements and such movement that is done to convey a particular work it is termed as gesture. If we want digital world to understand this gesture we need to interface this gesture into a form of signal that may be analog or digital.

Initally, the controller detects open or close fist, which makes the bot or the gripper move, and this can be achieved by using a pushbutton switch at the center of palm.

After the observation, movement of hand actually changes the position of it with reference to ground so that it can give electrical signal according to the change in its position which is perfectly done by the module MPU-6050 (as shown in fig.2) which is a 5 pin i2c compatible module with 6 dof to recognize its position perfectly, the module is attached to the palm of hand which detects wrist movement and gives electrical signal accordingly.

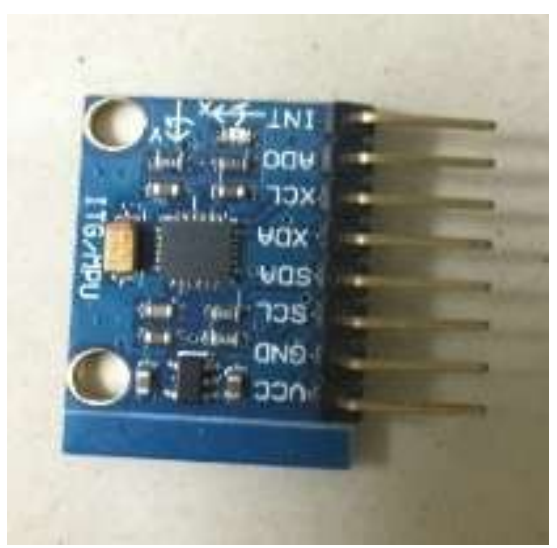

Fig 3
According to the InvenSense MPU-6050 datasheet, this chip contains a 3 -axis gyroscope and a 3 -axis accelerometer. This makes it a " 6 degrees of freedom inertial measurement unit" or 6DOF IMU, for short. Other features include a built in 16-bit analog to digital conversion on each channel and a proprietary Digital Motion Processor ${ }^{\mathrm{TM}}$ (DMP) unit.

\subsection{A/D Converter}

Converting the analog signal to the digital form using microcontroller Arduino UNO does this section. This controller works on atmega-32 and is programed to interface with the GY-251 module with i2c interfacing. Here the sensor signal is converted into four bit data (according to either switch press or release state) that is the conversion of analog signal to the digital ones. The connection of the module is given in the picture below:

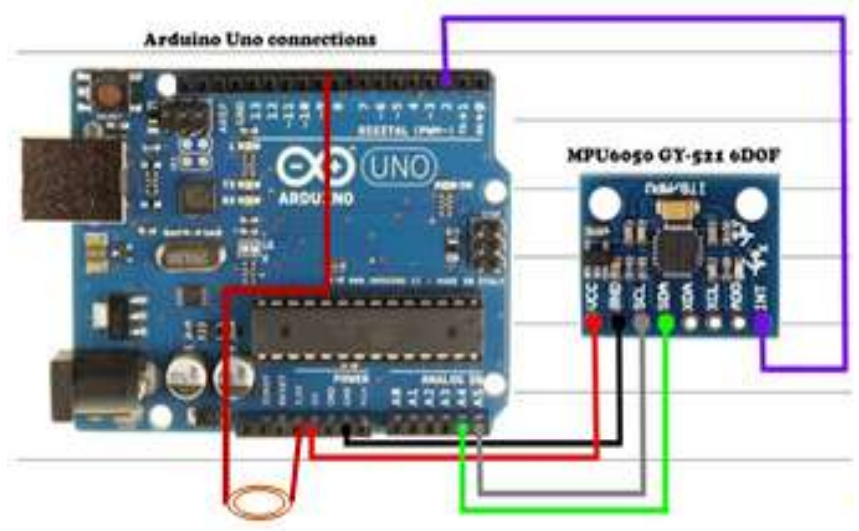

Fig 4

Picture courtesy:http://42bots.com/tutorials/arduino-unoand-the-invensense-mpu-6050-6dof-imu/ 


\subsection{Transmitter}

Here the 4-bit parallel data is converted into 12-bit serial data with 8-bit addressing mode using the IC HT12E, which has an internal crystal and converts the parallel data in serial data with 8-bit address. Here transmitting it through air using RF-Transmitter of $433 \mathrm{MHz}$ does modulation of the signal.

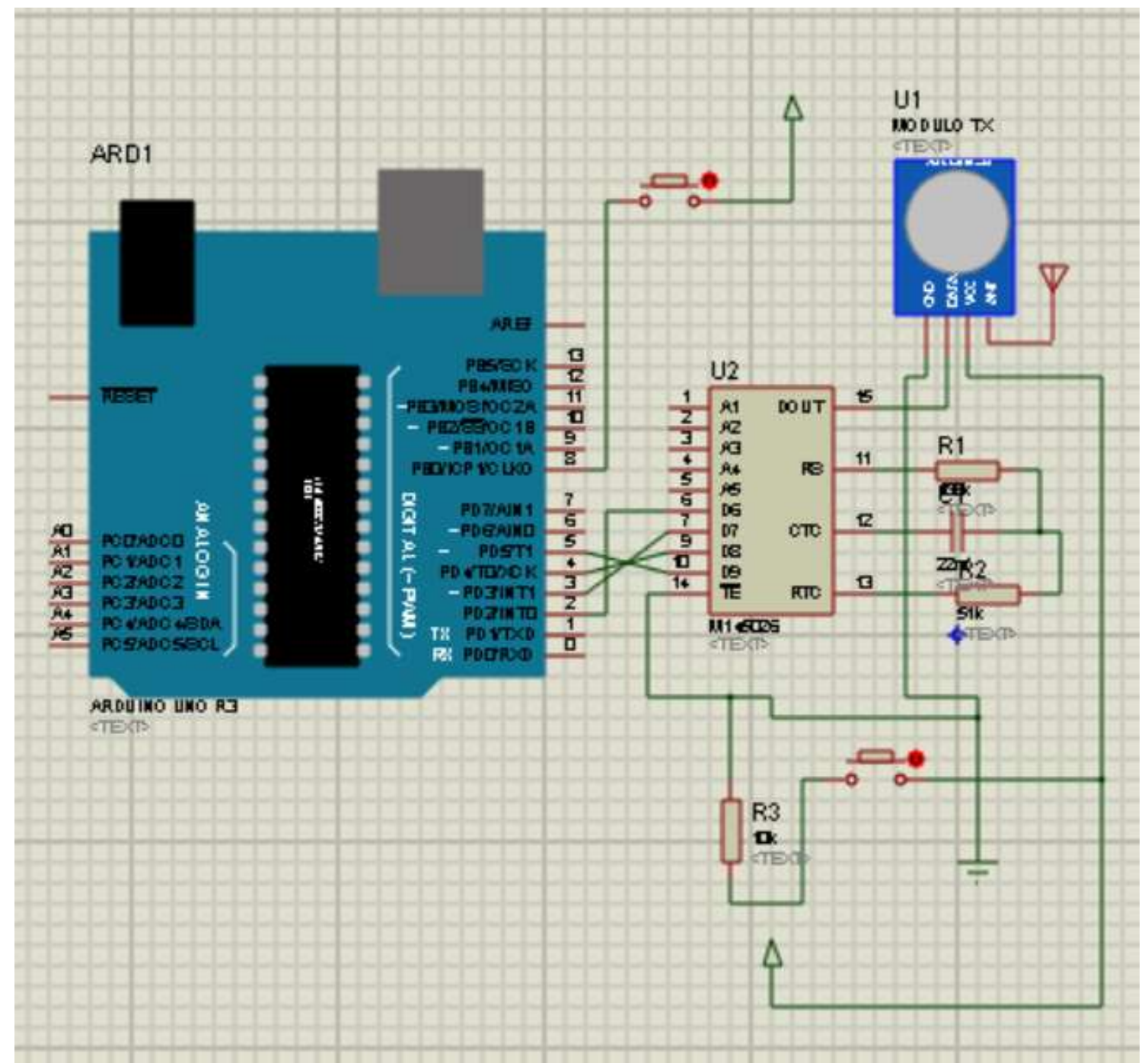

Fig 5

In figure.5, 4-bit data from Arduino is sent over HT12E with 8-bit address then the output is sent to the RF-Transmitter to the open air. The transmitter works on ASK modulation for signal transmission.

The complete transmitter, which can detect the gesture of the hand and transmit it over RF signal to the receiver prototype, is given below.

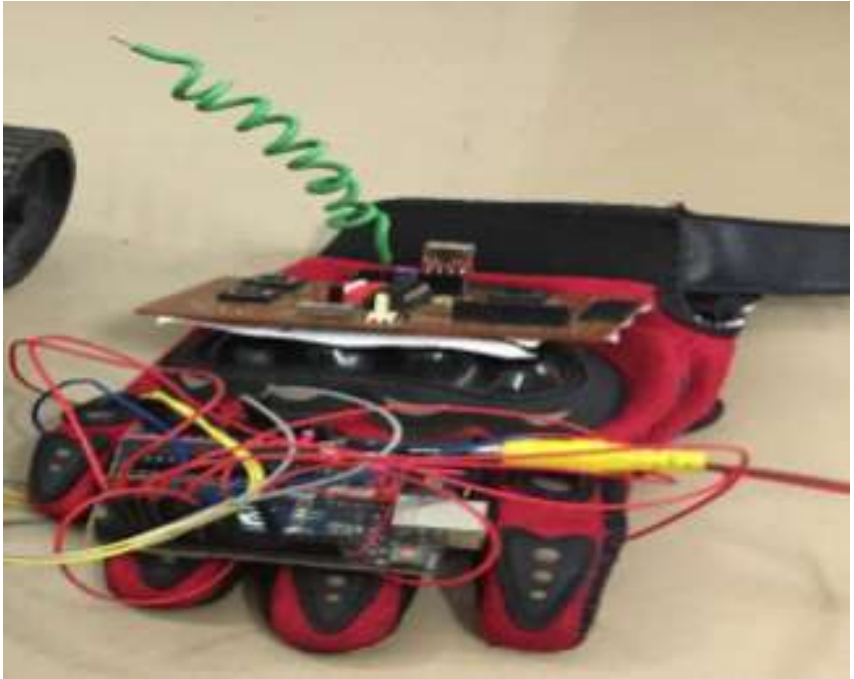

Fig 6 Prototype of a Transmitter 


\section{RECEIVER SECTION}

Here the overall circuitry can be explained in the three part, where the bot receives the signal, decodes, generates a suitable power and controls the correct motor or actuator, which can be explained by the flow below.

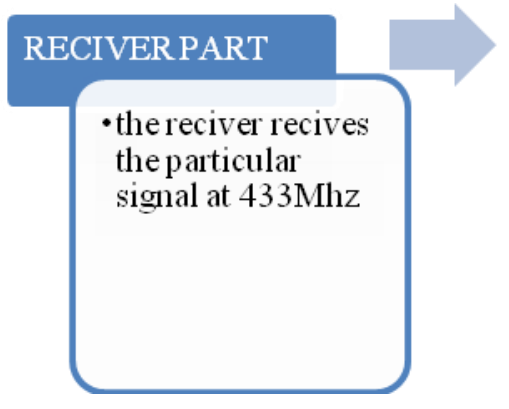

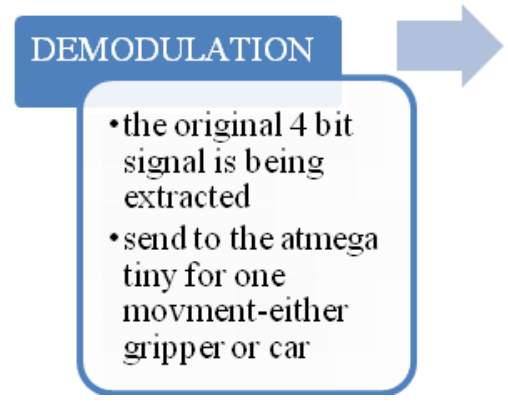

Fig 7

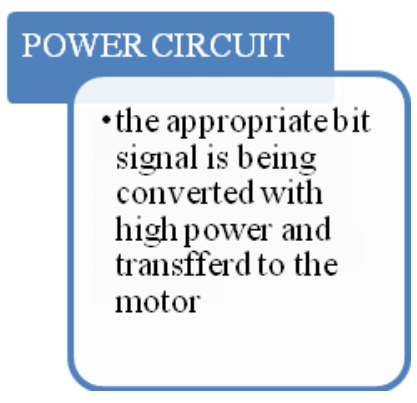

This is the interesting part of the project where the gesture motion is actually being transmitted to a robocar, which performs its locomotion according to the gesture signal assigned in transmitter section. The RF-receiver is used take the signal transmitted and it passes over to the HT12D decoder which is actually addressed same as the transmitter to reconstruct the original signal. After the 4-bit data is retrieved, it is passed to the buffer and relay for high power response of the battery to actuator.

Table 1: Configuration of actuators

\begin{tabular}{|c|c|c|c|c|c|c|}
\hline $\begin{array}{l}\text { Receiver } \\
\text { side } \\
\text { gesture }\end{array}$ & $\begin{array}{l}\text { Receiver } \\
\text { side } \\
\text { gesture }\end{array}$ & $\begin{array}{l}\text { Bit } \\
1\end{array}$ & $\begin{array}{l}\text { Bit } \\
2\end{array}$ & $\begin{array}{l}\text { Bit } \\
3\end{array}$ & $\begin{array}{l}\text { Bit } \\
4\end{array}$ & $\begin{array}{l}\text { Condition } \\
\text { of motor }\end{array}$ \\
\hline \multirow{5}{*}{$\begin{array}{l}\text { Palm } \\
\text { open }\end{array}$} & $\begin{array}{l}\text { Supine } \\
\text { position }\end{array}$ & 0 & 0 & 0 & 0 & $\begin{array}{l}\text { No } \\
\text { movement }\end{array}$ \\
\hline & $\begin{array}{l}\text { Wrist tilt } \\
\text { UP }\end{array}$ & 0 & 0 & 0 & 1 & $\begin{array}{l}\text { Forward } \\
\text { movement }\end{array}$ \\
\hline & $\begin{array}{l}\text { Wrist tilt } \\
\text { DOWN }\end{array}$ & 0 & 0 & 1 & 0 & $\begin{array}{l}\text { Backward } \\
\text { movement }\end{array}$ \\
\hline & $\begin{array}{l}\text { Wrist tilt } \\
\text { RIGHT }\end{array}$ & 0 & 0 & 1 & 1 & Right turn \\
\hline & $\begin{array}{l}\text { Wrist tilt } \\
\text { LEFT }\end{array}$ & 0 & 1 & 0 & 0 & Left turn \\
\hline \multirow{5}{*}{$\begin{array}{l}\text { Palm } \\
\text { closed }\end{array}$} & $\begin{array}{l}\text { Supine } \\
\text { position }\end{array}$ & 1 & 0 & 0 & 0 & $\begin{array}{l}\text { No } \\
\text { movement }\end{array}$ \\
\hline & $\begin{array}{l}\text { Wrist tilt } \\
\text { UP }\end{array}$ & 1 & 0 & 0 & 1 & $\begin{array}{l}\text { Gripper } \\
\text { up }\end{array}$ \\
\hline & $\begin{array}{l}\text { Wrist tilt } \\
\text { DOWN }\end{array}$ & 1 & 0 & 1 & 0 & $\begin{array}{l}\text { Gripper } \\
\text { down }\end{array}$ \\
\hline & $\begin{array}{l}\text { Wrist tilt } \\
\text { RIGHT }\end{array}$ & 1 & 0 & 1 & 1 & $\begin{array}{l}\text { Gripper } \\
\text { close }\end{array}$ \\
\hline & $\begin{array}{l}\text { Wrist tilt } \\
\text { LEFT }\end{array}$ & 1 & 1 & 0 & 0 & $\begin{array}{l}\text { Gripper } \\
\text { open }\end{array}$ \\
\hline
\end{tabular}

\subsection{Bit Stream Configuration}

Now, as we recived the four bit data we assign each data to perform different task accordingly for doing so we will program the atmega tiny 24 for controlling 10 different motion of motors the tiny is being programmed using the Arduino uno which was used in the reciver .The main reason to use controller to reduce the circuit complexity and reduce the task of digital circuit implementation. The figure below show how to program the atmegatiny 24 ic sing Arduino.

Afer the output of each motor is passed through the power circuit using L293d motor driver ic for high torque .

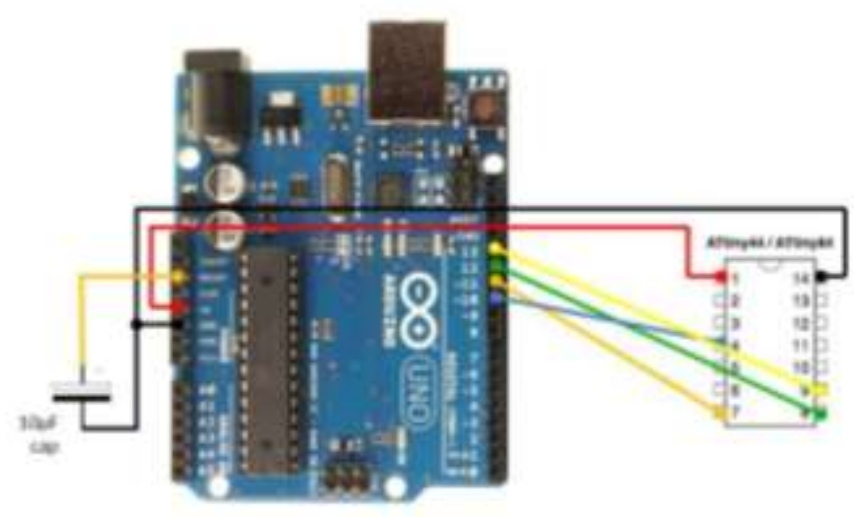

Fig 8

Picture courtesy: http://duino4projects.com/using-thearduino-uno-to-program-attiny84-20pu/

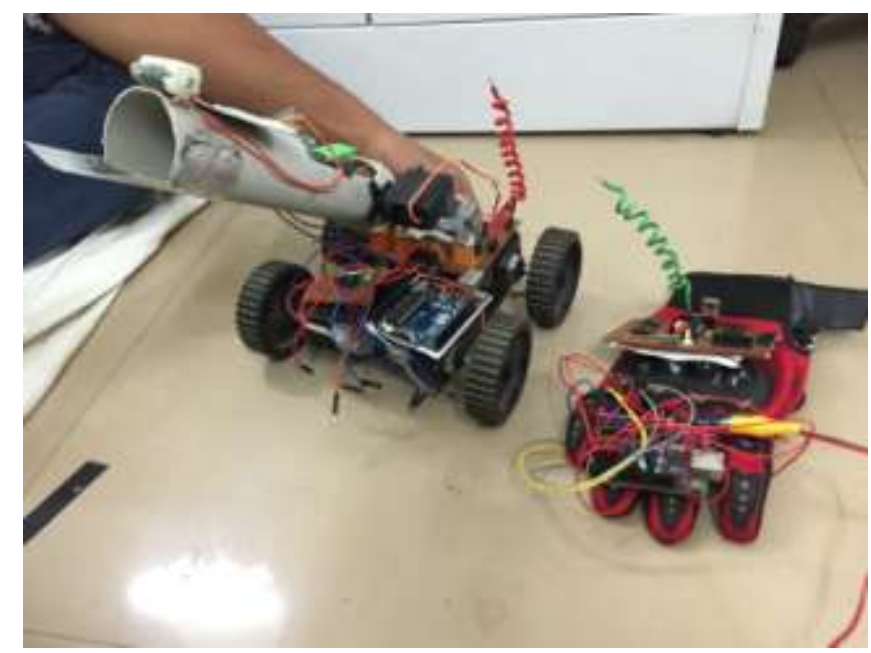

Fig 7 Complete image of the project 


\section{FUTURE SCOPE}

As the project is concerned with the work on the basis of gesture of hand or arm it is the new era of advance automation to control robotic machine more precisely up to the level of human hand movement, and the project can also be used for the disabled person who can't move. It will be useful for operating or observing the machine through gesture of hand,neck or any other part of the body movement. Till now the car is designed for the eight channel working and can be advancedupto 16 channel by just advancing the digital circuit in the receiver and coding at the transmitter.

\section{CONCLUSION}

The overall effort is made to reduce the effort of human not only in the field of machine by automation but also to design the project for the same with the most simplest way by simply replacing the receiver section with totally digital one. Hence the project can be expanded further to achieve a new height of automation in terms of gesture of the human body or can be designed to shadow robot.

\section{ACKNOWLEDGEMENT}

The author wishes to acknowledge the department of Electronics \& Telecommunication department to provide the full laboratory support for doing this research. This research was conducted at BVM Engineering College, Anand. The author also wishes to acknowledge to Associate Professors of the college to provide the research guidance.

\section{REFERENCES}

[1]. http://playground.arduino.cc/Main/MPU-6050

[2]. http://www.instructables.com/id/Gesture-controlledrobot using Arduino/

[3]. RF Based Wireless Remote using RX-TX MODULES (434MHz.) by STrobotix

[4]. Remote-Controlled landrover-a DIY robotic project occupied from www.EFYMAG.com

[5]. http://duino4projects.com/using-the-arduino-uno-toprogram-attiny84-20pu/

[6]. http://www.instructables.com/id/Program-an-ATtinywith-Arduino/[*]from my old paper on performance analysis of gesture control car in ijret.

\section{BIOGRAPHIES}

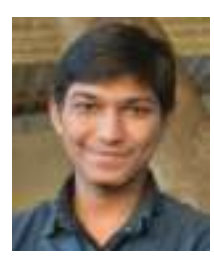

Mohit Agarwal currently pursuing B.E. ET at BVM Engineering College. His current research interests are gesture based system and communication system.

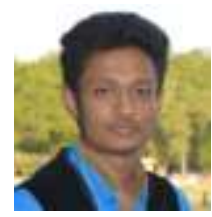

Mukesh Chheta currently pursuing B.E. ET at BVM Engineering College. His current research interests are gesture based system and communication system.

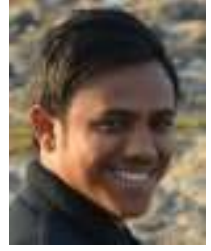

Aliraza Hasan currently pursuing B.E. ET at BVM Engineering College. His current research interests are gesture based system and communication system.

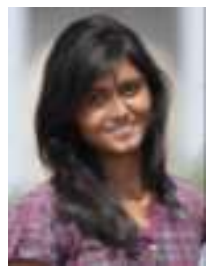

Samriddhi Singh currently pursuing B.E. ET at BVM Engineering College. Her current research interests are gesture based system and communication system. 